\title{
Consumo: uma construção identitária cultural na sociedade contemporânea ${ }^{1}$
}

\author{
Consumption: a cultural identity construction in the contemporary society
}

\author{
Evelyse Kaminski
}

Graduada em Comunicação Social, Habilitação em Publicidade e Propaganda, Especialista em Docência para o Ensino Superior e Mestranda do curso de Comunicação e Linguagens da Universidade Tuiuti do Paraná (UTP), Curitiba, PR - Brasil, e-mail: ve_kami@ yahoo.com.br

\section{Resumo}

Construção identitária cultural e consumo implicam a marca de um produto que seduz o consumidor, transferindo-lhe significados simbólicos. Por meio de uma pesquisa bibliográfica, o objetivo deste artigo é apontar alguns recortes teóricos que permeiam e facilitam a compreensão do processo construtivo da identidade do consumidor e da marca, especialmente a de luxo, uma vez que esta também possui uma identidade que a particulariza. Busca ainda mostrar a importância das estratégias enunciativas nesse contexto. Para isso, as teorias de David Aaker, Mauro C. Tavares, Antonio C. Ciampa, Gilles Lipovetsky e Zygmunt Bauman estão presentes nesse estudo.

Palavras-chave: Comunicação. Identidade. Marca de luxo. Cultura.

\begin{abstract}
Cultural identity construction and consumption imply the brand of a product that seduce consumer and give them symbolic meaning. Through literature research, this paper aims to indicate some theoretical framework that permeate and facilitate understanding the construction process of the identity of consumer and brand, especially the luxury ones, since they also owns an identity that particularizes them. Still, shows the importance of enunciative strategies in this context. Therefore, the theories of de David Aaker, Mauro C. Tavares, Antonio C. Ciampa, Gilles Lipovetsky e Zygmunt Bauman are used in this study.
\end{abstract}

Keywords: Communication. Identity. Luxury brand. Culture.

1 Artigo apresentado a partir de reflexões que integram o projeto de pesquisa intitulado "A representação da marca de luxo no cinema: Breakfast at Tiffany's e The Devil Wears Prada". 


\section{Introdução}

Refletir sobre a formação identitária cultural da sociedade contemporânea e sua relação com o consumo é um desafio, haja vista que os consumidores são voláteis e irrequietos diante de tantos acontecimentos cotidianos, inclusive perante o bombardeio de informações e ofertas às quais são expostos. Com isso, as estratégias de comunicação e marketing precisam ser renovadas constantemente para acompanhar as mutações comportamentais e culturais da sociedade.

Um elemento importante nessa relação é a marca do produto/serviço e suas estratégias enunciativas, articuladas para seduzir e despertar o desejo do consumidor a fim de impulsioná-lo a adquirir o produto anunciado. Nessa linha, o objetivo deste trabalho é demonstrar como o consumo pode influenciar a construção cultural da sociedade e de que modo a apropriação dessa identidade social ocorre para gerar o consumo por meio das estratégias enunciativas da marca. Além disso, a importância da marca de luxo nesse ciclo identitário social também será abordada.

Para melhor compreensão do tema abordado, este artigo traz teorias que perpassam, principalmente, o campo da comunicação e da psicologia no que tange à formação da identidade do sujeito social e da marca, uma vez que ambos necessitam se destacar dos demais componentes que os cercam. Portanto, por meio dessa estrutura teórica, acreditamos atender aos objetivos deste estudo e estimular reflexões sobre o papel e o efeito de sentido que as ações com foco na marca podem produzir na sociedade contemporânea.

\section{Identidade: entre o sujeito social e a marca}

Inicialmente, vale ressaltar que o termo identidade não é algo rígido e acabado, mas se trata de estudos e pontos de vista de diferentes áreas do conhecimento. Retratar a identidade por inteiro é um trabalho complexo, graças aos seus diferentes aspectos. Portanto, buscou-se, por meio de alguns recortes teóricos, abordar a construção da identidade do sujeito relacionando-a com o processo construtivo de uma marca. Para tanto, neste estudo, optou-se pela interface entre os campos da psicologia e da comunicação.

A identidade é conquistada e adquirida ao longo da existência do ser humano; isto é, forma-se a partir da infância e da trajetória de cada um. Pode ser construída a partir do ponto de intersecção entre duas partes, uma sendo algo pessoal inerente ao homem e a outra, algo externo que age sobre ele. Esse agir, normalmente, é efetuado pela sociedade, que dita regras de comportamento. A partir disso, experiências são trocadas por meio do convívio com outras pessoas, iniciando assim a construção da identidade.

Trata-se de um processo contínuo que perpassa a trajetória do sujeito e tem como objetivo apresentá-lo ao mundo e, ao mesmo tempo, particularizá-lo, tornando-o único diante das outras pessoas. Para o pesquisador Antonio Carlos Ciampa (1990, p. 127), "[...] as identidades constituem a sociedade, ao mesmo tempo em que são constituídas, cada uma por ela”. Assim, a identidade do sujeito está diretamente ligada à diferenciação e às atribuições de significados a partir da relação com os outros.

Ainda para o autor, o nomeé uma representação de identidade. "A identidade, que inicialmente assume a forma de um nome próprio, vai adotando outras formas de predicações, como papéis, especialmente" (CIAMPA, 1990, p. 134). Dessa forma, ao se pensar no nome próprio e sobrenome que cada sujeito possui, pressupõe-se que eles se diferenciam uns dos outros, porém, na realidade, trata-se do ponto inicial de distinção da identidade.

O sujeito inicia o processo de identificação com o mundo além do seu relacionamento materno e começa a perceber que outras pessoas podem tornar-se sua referência e, por meio de um processo de identificação, começa a formação da identidade. Assim, os aspectos importantes que o sujeito traz como referências são responsáveis pela busca constante da construção de identidade.

Com o decorrer de sua vida, o sujeito se relaciona com o meio externo e tem novas experiências, o que faz sua identidade sofrer mutações. Essas transformações acrescentam impressões que determinam o reconhecimento e a identificação diante dos demais. "Identidadeéhistória. Isto nos permite afirmar que não há personagens fora de uma história, assim como não há história (ao menos história humana) sem personagens" (CIAMPA, 1990, p. 157).

A partir do pressuposto supracitado, traçaremos um paralelo entre a construção da identidade do sujeito, assim como da marca de um produto, a fim de analisar a maneira como ocorre a apropriação da 
identidade do sujeito para que a marca construa sua própria identidade - uma vez que ela também busca individualidade e diferenciação diante da concorrência - e o modo como a cultura social modifica-se a partir das marcas consumidas.

Para este estudo, adotaremos a ideia de que a construção da identidade é o processo de formação contínua que acontece ao longo da existência do sujeito, ou seja, é formada a partir das experiências vividas e compartilhadas com o ambiente que o cerca. Além disso, a identidade confere significado e proporciona sentido às pessoas, particularizando-as.

Assim, de maneira semelhante ao que ocorre com o indivíduo, a marca constitui uma identidade que carrega consigo todos os aspectos acumulados em sua trajetória. Dessa forma, percebe-se que um de seus objetivos é diferenciar um produto/empresa dos demais da sua categoria. Nesse momento, iniciase seu processo de construção de identidade, uma vez que a marca possui um nome próprio que serve como elemento de diferenciação.

Inicialmente, a identidade da marca acumula valores da empresa/produto que representa, como, por exemplo, visão e missão:

A identidade deve facilitar a compreensão dos valores e dos propósitos básicos da empresa. Deve, ainda, refletir os aspectos da crença cultivados pela empresa, como o padrão de qualidade adequado à sua evolução, sua sensibilidade às mudanças nos estilos de vida, inovação tecnológica e posicionamento em face das forças competitivas (TAVARES, 2008, p. 159).

O processo de construção de identidade da marca tem continuidade por meio da relação com o ambiente mercadológico em que se insere, ou seja, as situações recorrentes no mercado competitivo motivam as ações de marketing e comunicação, que agem diretamente na formação da identidade da marca.

A imagem de um produto divulgado na mídia pela propaganda fará com que as pessoas reconheçam e sintam-se seduzidas a consumir a marca, graças à maneira como foi exposta - como acontece, por exemplo, com a marca $\mathrm{Bic}^{\circledR}$ de canetas, que foi apresentada para o público como uma caneta popular, que todos gostariam de ter. Essas características, componentes da sua identidade, fazem com que a reconheçamos diante das demais canetas.
O fundamento para o estabelecimento das relações do consumidor com a empresa é a imagem formada a partir da percepção de sua identidade. A marca sintetiza essa identidade por meio de suas características e atributos e simboliza esse relacionamento através de seus benefícios funcionais, experienciais e simbólicos, além de suas associações primárias e secundárias (TAVARES, 2008, p. 161).

Vale ressaltar que a identidade da marca também sofre alterações de acordo com as diferentes fases pelas quais passa. Por mais que se modifique, há resquícios que permitem o seu reconhecimento, positiva ou negativamente. Por exemplo, a marca Nike $^{\circledR}$ já atravessou diferentes fases, porém um momento conturbado foi o lançamento de um tênis que tinha uma parte em metal e esse detalhe provocou cortes nas pernas de seus usuários. Após receber tantas reclamações, a empresa recolheu todos os tênis do mercado e recompensou seus consumidores com novos produtos. A ação de marketing realizada para reverter tal situação foi válida para encobrir o problema e apontar uma nova fase para a marca Nike $^{\circledR}$. No entanto, não apagou a mancha deixada por aquela falha.

Em uma visão estratégica, a identidade é essencial para agregar valores e significados a uma marca. Da mesma maneira, como alguém pode ser reconhecido por características positivas ou negativas, a marca também apreende valores que dependem de associações feitas pelo consumidor:

A imagem e a reputação corporativa podem ser um espelho acurado de sua identidade e guardar uma forte coerência com seu posicionamento, pode também, por vezes, ser inconsistente por falhas nas estratégias de comunicação e erro nas ações desenvolvidas (TAVARES, 2008, p. 159).

$\mathrm{Na}$ construção da identidade, há um processo de identificação que acontece a partir da seleção daquilo que nos atrai e que parece nos interessar. $\mathrm{Na}$ relação entre marca e consumidor ocorre da mesma forma, isto é, o consumidor se identifica com a marca quando ela representa valores positivos e oferece-lhe benefícios. Porisso, aidentidade da marca deve trazer consigo características da identidade do próprio consumidor alvo, tendo em vista suas necessidades e aspirações. "A identidade da marca 
deve ajudar a estabelecer um relacionamento entre a marca e o cliente, por meio de uma proposta de valor envolvendo benefícios funcionais, emocionais ou de auto-expressão" (AAKER, 2007, p. 74).

O valor de uma marca está diretamente ligado aos traços de sua identidade e se concretiza por meio de ações de marketing e comunicação desenvolvidas para criar um bom posicionamento diante do público de interesse. Essas ações procuram transmitir valores e significados para os consumidores e os demais interessados na marca, com o objetivo de fazer com que todos se identifiquem e criem uma relação de proximidade. Dessa maneira, a comunicação e o marketing desempenham um papel importante no estabelecimento dessa relação, pois, por intermédio de uma estratégia de posicionamento, a identidade da marca é apresentada para o público de modo bem afeiçoado, com características que facilitam o processo de identificação entre eles.

Ao traçarmos aqui alguma noção de identidade, tanto do sujeito quanto da marca, podemos observar que sua formação parte de um processo de identificação em três vertentes: do sujeito para com os outros membros sociais, da marca para com o consumidor e do consumidor para com a marca.

No primeiro caso, a identidade do sujeito se forma por meio de escolhas referenciais e da influência do meio que o cerca. Já no segundo caso, a marca pode influenciar diretamente a construção da identidade do sujeito social, visto que ele a compra com intenção de suprir suas necessidades e aspirações. No terceiro caso, os traços agregados à marca são influenciados pelos consumidores, pois as ações voltadas para o seu posicionamento são elaboradas para atender aos desejos desse público. Assim, naturalmente se constata que o consumidor influencia diretamente no processo de construção da identidade da marca, assim como a identidade da marca influencia diretamente a formação da identidade do consumidor.

\section{A busca pela individualidade no consumo contemporâneo}

O consumo está presente no cotidiano da sociedade contemporânea, independentemente da sua intensidade. É possível observar a maneira como este ato, aparentemente comum, atua e age diretamente na formação de grupos, modificando culturalmente a sociedade. Vale lembrar que o consumo é estimulado por estratégias enunciativas de marketing e comunicação que são articuladas para que as marcas consumidas sejam inseridas na vida dos consumidores de tal forma que cheguem a influenciar a formação de suas identidades.

A circulação excessiva de informações que se altera em grande velocidade é, por exemplo, um dos fatores que age diretamente nas possíveis mudanças que ocorrem na construção da identidade do sujeito. $\mathrm{Na}$ medida em que ocorrem essas mutações na personalidade do público, as estratégias de marketing e comunicação enfrentam o desafio de conquistar e manter consumidores a fim de sustentar a competitividade mercadológica; sendo assim, o elemento de destaque passa a ser a marca do produto ofertado.

Zygmunt Bauman (2007) define a sociedade atual como "líquido-moderna" e diz que os membros da sociedade são inquietos e voláteis, pois não possuem hábitos, rotinas ou uma forma de agir específica e única. Para o autor, as alterações acontecem mais rápidas do que a concretização das características e costumes vividos pela sociedade.

No que se refere ao consumo, evidenciamos o desapego do público em relação a produtos e marcas. Torna-se mais comum substituir seus pertences do que mantê-los - principalmente no que se refere à tecnologia. $\mathrm{O}$ fato de o público não possuir apego e frequentemente trocar seus produtos para a aquisição de novos evidencia que o consumo é um processo contínuo e intenso na atual conjuntura. Além disso, há uma perda do cliente fiel, fato que aumenta o desafio das estratégias enunciativas na conquista e, principalmente, na manutenção do consumidor; portanto, cada vez mais as estratégias são intensificadas e agem diretamente na construção da identidade social, ditando costumes e comportamentos.

A desatualização das linhas de produtos leva alguns consumidores a pensar que fidelidade é sinônimo de atraso. Porém, a marca que acompanha mudanças tecnológicas - inovando constantementeconsegue manter clientes fiéis e satisfeitos.

Uma marca que mantém sua linha de produtos atualizada e acompanha as evoluções tecnológicas consegue agregar valores positivos à sua identidade e manter um bom posicionamento na mente do consumidor, facilitando a fidelização dos clientes. Assim, as estratégias enunciativas com foco na marca são um meio de manter o produto competitivo no mercado atuante. 
Por exemplo, se uma marca de telefone celular atrasa a inovação em sua linha de produtos, é provável que seu consumidor migre para as marcas concorrentes. No entanto, se essa marca inovar com frequência para acompanhar o ritmo das mudanças e mantiver bons valores conceituais agregados, reduzse a probabilidade de perder consumidores, pois o atual telefone celular pode ser substituído por outro mais novo e da mesma marca.

Demaneira geral, segundo Bauman(2007,p. 17-18), tudo o que não acompanha as rápidas mudanças da sociedade contemporânea é denominado "lixo":

O lixo é o principal e, comprovadamente, o mais abundante produto da sociedade líquidomoderna de consumo. Entre as indústrias da sociedade de consumo, a de produção de lixo éa mais sólida e imune a crises. Isso faz da remoção do lixo um dos dois principais desafios que a vida líquida precisa enfrentar e resolver. O outro é a ameaça de ser jogado no lixo. Em um mundo repleto de consumidores e produtos, a vida flutua desconfortavelmente entre os prazeres do consumo e os horrores da pilha de lixo.

Nessa constante troca de produtos antigos e ultrapassados por produtos atualizados e modernos, começam a se formar novos membros sociais com traços particulares. Nesse sentido, o consumo e o desejo de consumir compõem a formação da identidade de cada um.

Ao falarmos de identidade, referimo-nos, primeiramente, à diferenciação do sujeito em relação ao outro e à sua individualidade. O processo de identificação na sociedade contemporânea faz com que as pessoas sejam divididas em grupos sociais de acordo com seus hábitos e costumes. No entanto, no que se refere ao consumo, muitas pessoas buscam nos produtos e marcas valores que os diferenciam dos demais membros sociais ou valores que os incluam em determinado grupo:

O território da construção e reconstrução da identidade não é a única conquista da síndrome do consumo, além do reino das ruas luxuosas e dos shoppings centers. De forma gradual, mas incansável, toma conta das relações e dos vínculos entre os seres humanos (BAUMAN, 2007,p. 115).

$\mathrm{Na}$ busca incessante por marcas dotadas de valores conceituais únicos, cria-se a ilusão da exclusividade. Mas, ao mesmo tempo, o sujeito também absorve características semelhantes às de um grupo específico do qual passa a fazer parte. Por exemplo, um grupo que geralmente aprecia a noite, veste-se com roupas de cor preta e usa maquiagens sombrias é classificado como gótico. Aqueles que buscam ser diferentes das outras pessoas e se caracterizam dessa maneira serão igualmente classificados como góticos. Isto é, por mais diferentes que possam parecer, características semelhantes os tornam membros do mesmo grupo.

Por aí se vê que a oposição posta em evidência entre individualismo e "tribalismo" pós-moderno é perfeitamente artificial e enganosa: a despeito de sua dimensão comunitária, a marca exibida é subjetivante, ela traduz, ainda que na ambigüidade, uma apropriação pessoal, uma busca de individualidade assim como um desejo de integração no grupo dos pares, um eu reivindicando, aos olhos de todos, os signos de sua aparência (LIPOVETSKY, 2007, p. 51).

Na sociedade contemporânea, a individualidade de cada consumidor perde a força na medida em que grupos seguem passos semelhantes e utilizam símbolos comuns, compartilhando experiências:

Numa sociedade de indivíduos, cada um deve ser um indivíduo. A esse respeito, pelo menos, os membros dessa sociedade são tudo menos indivíduos diferentes ou únicos. São, pelo contrário, estritamente semelhantes a todos os outros pelo fato de terem de seguir a mesma estratégia de vida e usar símbolos comuns comumente reconhecíveis e legíveis - para convencerem os outros de que assim estão fazendo (BAUMAN, 2007, p. 26).

É no mínimo curioso pensar que, a partir do consumo, o público busque a diferenciação e o destaque; no entanto, ao consumir uma marca específica, o indivíduo apenas se disfarça com símbolos dotados de valores que o aproximam e o tornam semelhante a determinados grupos.

Valendo-se dos impulsos e dos desejos do ser humano de querer ser único, as empresas divulgam conceitos atraentes que levam o sujeito a crer que, adquirindo o produto anunciado, a exclusividade é conquistada. Assim, na busca intensa de 
satisfazer seus desejos, o público aceita a mensagem e consome a marca anunciada.

Bauman (2007) afirma ainda que a individualidade no mundo contemporâneo significa ter controle sobre si mesmo, ou seja, cada um é responsável pelos seus próprios atos, seja para satisfazer os desejos do id ${ }^{2}$ ou não. Para Lipovetsky (2007), surge o consumo individualista em que as pessoas consomem sem pensar no outro e buscam apenas satisfações pessoais. Nesse caso, também ocorre a individualidade mascarada, pois os valores conceituais dos produtos adquiridos são transferidos para quem os consome e, consequentemente, julgados pelos demais integrantes sociais, diferenciando assim um sujeito do outro e criando uma identidade cultural.

Mas não é menos verdade que, durante esse ciclo, o consumo conservou um forte potencial de prestígio, não deixando os objetos como signos tangíveis de sucesso, provas de ascensão e de integração social, vetores de consideração honorífica (LIPOVETSKY, 2007, p. 40).

Mais uma vez, o consumo desempenha um papel importante e ativo sobre a perspectiva de vida do ser humano, por isso, as marcas seduzem, atraem e incentivam o público a efetivar a compra, por meio de mensagens personalizadas que convencem e manipulam o consumidor.

Os movimentos do mercado de consumo desafiam a lógica, mas não a da luta já inerentemente aporética pela individualidade. Uma propaganda como "Seja você mesmo - prefira Pepsi" faz eco a essa aporia com uma franqueza muito bem vinda pelos consumidores potenciais do produto e à qual seriam gratos (BAUMAN, 2007, p. 36).

No dinamismo da atual sociedade, a individualidade deve ser encarada como um privilégio para quem consegue tê-la.

[...] a individualidade é e deverá continuar sendo por muito tempo um privilégio. Um privilégio dentro de cada uma das sociedades, quase autônomas, em que o jogo da auto-afirmação é levado à frente por meio da separação entre os consumidores "emancipados", plenamente desenvolvidos - lutando para compor e recompor suas individualidades singulares a partir de "edições limitadas" dos últimos modelos da alta-costura -, e a massa sem rosto dos que estão "presos" e "fixos" a uma identidade sem escolha, atribuída ou imposta, sem perguntas, mas em todo caso "superdeterminada"(BAUMAN,2007,p.39).

Podemos dizer, então, que a individualidade e a identidade estão entrelaçadas e são complementares. A formação da identidade ocorre a partir de referências escolhidas para a diferenciação entre os sujeitos, ou seja, eles se identificam e consomem produtos dotados de símbolos quelhes causam a sensação de individualidade e, assim, influenciam na formação de sua identidade e, consequentemente, constroem uma identidade social.

Os impulsos e os desejos do sujeito movem a sociedade do consumo, pois enquanto reina a insatisfação em cada membro da sociedade, a marca se torna o elemento alvo que busca substituir o objeto de desejo almejado pelo sujeito. Uma maneira de manter o ciclo da insatisfação no mercado de consumo é desatualizar rapidamente os produtos que são lançados, o que aumenta a pilha de "lixo".

Uma estratégia mercadológica utilizada por empresas é o lançamento de novos produtos com tecnologias mais avançadas e design arrojado. Por exemplo, cada vez mais os telefones celulares seduzem a sociedade com tecnologia de ponta e utilidades variadas como reprodução de vídeos eimagens, conexão à internet, reprodução de arquivos em formatos diversos, etc. Dessa maneira, a insatisfação do consumidor se mantém ativa, pois as novidades despertam o desejo do consumo e a sensação de que seu atual produto precisa ser substituído.

É importante ressaltar que a constante e intensa insatisfação pode gerar um quadro patológico, como a compulsão ou o vício do consumo. Não convém tratar desse aspecto neste artigo; portanto, a insatisfação citada aqui é retratada no sentido de despertar o desejo do consumo moderado que é o responsável pela demanda de novos produtos, dando origem a um ciclo comercial e econômico.

\footnotetext{
2 De acordo com Freud, a parte primitiva da personalidade inconsciente, caracterizada por reações emocionais extremas e demandadas por gratificações imediatas. A função do id é satisfazer as necessidades instintivas, mas como funciona com base no princípio do prazer, ele pode ser satisfeito mediante a fantasia do objeto desejado. Por isso, o bebê deve começar a desenvolver o ego para lidar com a realidade (STRATTON; HAYES, 1994, p. 121).
} 
E é isso que ocorre, já que o impulso de buscar nas lojas e só nelas, soluções para os problemas e a alívio para as dores e a ansiedade é apenas um aspecto do comportamento que não apenas recebe a permissão de se condensar num hábito, mas é avidamente estimulado a fazê-lo (BAUMAN, 2007, p. 107).

A busca pela satisfação nada mais é do que a tentativa de ir ao encontro da felicidade, pois a sociedade moderna clama por prazeres e experiências vividas a cada dia e envolve-se em tudo o quelhe agrada.

Contudo, as promessas divulgadas e a imagem criada pelas marcas seduzem o consumidor para que ele busque na marca sua satisfação, até mesmo ultrapassando o âmbito da aquisição do produto - por exemplo, produtos falsificados que são consumidos pelo valor simbólico que representam.

No que diz respeito à construção identitária da sociedade contemporânea e ao consumo, pode-se afirmar que este elo surge a partir dos impulsos e dos desejos que se tenta suprimir com a aquisição de produtos com marcas que trazem significados relevantes. Convém ressaltar ainda que o ciclo do consumo ocorre paralelamente à busca incessante do sujeito por um objeto de completude, visto que o mercadode produtos está sempre inovando para incitar o público a consumir, e o consumidor, por sua vez, torna-se irrequieto com o lançamento de novos produtos. Dessa forma, a cadeia formada pela insatisfação seguida da tentativa de supressão dos desejos se torna constante, além de influenciar a sociedade do consumo.

Quanto mais se consome, mais se quer consumir: a época da abundância é inseparável de um alargamento indefinido da esfera das satisfações desejadas e de uma incapacidade de eliminar os apetites de consumo, sendo toda saturação de uma necessidade acompanhada imediatamente pornovas procuras (LIPOVETSKY,2007,p. 38).

Podemos dizer então que, na atual conjuntura, a sociedade é formada por consumidores, uma vez que ninguém está livre do consumo e todos praticam este ato, independentemente da intensidade e da preferência por uma determinada marca.

Um aspecto importante que se relaciona com a sociedade do consumo é o status, pois, diante das diferenças sociais, a utilização de uma marca pode classificar o sujeito como superior e causar, mais uma vez, a sensação de individualidade. "Nessa perspectiva, a corrida aos bens mercantis é inesgotável apenas na medida em que se apóia em lutas simbólicas com vista à apropriação dos signos diferenciais" (LIPOVETSKY, 2007, p. 39).

A diversidade de ofertas de produtos e de marcas lançadas no mercado confirma que o consumidor é volátil e preparado para analisar aquilo que lhe é proposto e, diante dessa realidade, as marcas buscam sermais pontuais em suas estratégias, na medida em que seus argumentos de venda relacionam-se aos critérios individuais de seu público de interesse. Nesse caso, ocorre a troca de valores entre os conceitos da marca e as características dos consumidores. E, dessa maneira, o consumo está relacionado à construção identitária da marca e, consequentemente, do consumidor.

Contudo, o status é suplantado pelos desejos experienciais dos consumidores, ou seja, o foco motivador da compra não é mais impressionar, e sim destacar a individualidade com a satisfação própria. "Na verdade, à medida que o consumidor se mostra menos obcecado pela imagem que oferece ao outro, suas decisões de compra são mais dependentes da dimensão imaginária das marcas" (LIPOVETSKY, 2007,p. 46). Assim, aumenta a importância do processo construtivo da marca na sociedade contemporânea, pois se uma marca possui um conceito bem projetado, pode adentrar a vida do consumidor a ponto de ousar preencher lacunas que porventura existam, influenciando na construção da sua identidade.

\section{Cultura e consumo na sociedade contemporânea}

Igualmente, as estratégias enunciativas utilizadas para estimular o consumo correlacionam-se com a formação cultural da sociedade.

Observaremos que a cultura pode ser refletida sob pontos de vista diferentes, quando ligada ao consumo. Isto é, por meio da marca adquirida, o senso comum pode nivelar culturalmente o consumidor.

Este artigo destaca a cultura sob dois aspectos: o primeiro, no que tange à visão antropológica, e o outro, sob o ponto de vista elitista. Assim, aponta o consumo como elemento que pode influenciar a construção da identidade cultural na sociedade contemporânea.

A cultura, no sentido antropológico, trata-se de uma espécie de interpretação da vida social, e não deve ser entendida apenas como forma de hierarquizar classes sociais ou indivíduos. Pode ser vista como a forma de vida de uma civilização, tornando, assim, cultura e sociedade inseparáveis. Nesse caso, a 
cultura pode ser um argumento comum entre grupos $\mathrm{e}$ isso faz com que seus integrantes convivam em harmonia, apesar das diferenças.

Conviver harmonicamente é uma norma social que facilita a relação entre as pessoas no meio em que vivem. Nesse viés, a cultura faz parte do processo de construção do humano. Dessa forma, ao relacionarmos a visão antropológica de cultura e consumo, é possível verificar que ambos são elementos que harmonizam o convívio social pois, ao utilizar uma marca, as pessoas são incluídas em determinados grupos e passam a compartilhar a mesma cultura, sem discriminação.

No ponto de vista elitista, a cultura é mantida como um elemento de diferenciação entre sujeitos ou classes sociais. Por exemplo, a pessoa que não possui determinado hábito cultural seria considerada inferior àquela que possui e, por isso, passa a ser discriminada. Esse fato pode estar correlacionado a bens materiais, ligando-se consecutivamente ao estilo de vida. Observa-se queuma pessoa que frequenta determinado lugar trajando roupas de marca de luxo é geralmente visto como "alguém de cultura", ou seja, dotado de conhecimentos que ultrapassam o senso comum. Nesse ponto de vista, verifica-se que a cultura é influenciada pela sociedade de consumo, visto que é mais um elemento interligado ao sujeito social.

A relação entre sociedade de consumo e cultura ocorre por causa das regras estabelecidas e conceitos preexistentes que ditam o comportamento e a harmonia no convívio entre os membros sociais. Ou seja, o consumo passa a ser um elemento que auxilia-por meio dos símbolos das marcas adquiridas - no julgamento das diferentes formas de cultura, o que geralmente é alvo de julgamento hierárquico.

Essa forma de hierarquização - traço da visão elitista - faz com que as pessoas tenham uma visão reducionista do outro. Já na visão antropológica, a cultura serve para harmonizar a convivência em sociedade como elemento indispensável.

Por fim, é possível observar que, assim como se dá com a construção da identidade do sujeito e da marca, ocorre com a construção da identidade cultural da sociedade, pois esta pode ser construída a partir do consumo e modificar-se de acordo com as mutações sociais.

\section{Considerações finais}

Diante das considerações aqui apontadas, constatamos um ciclo vicioso no que se refere ao consumo e à construção e mutação da identidade dos três elementos estudados: sujeito; marca e sociedade.
A identidade do sujeito é construída a partir das suas relações com o meio que o cerca. Nessa vertente, o consumo está presente diariamente, integrando-se nesse ciclo. Valendo disso, as marcas constroem suas identidades de acordo com que o consumidor almeja, a fim de complementá-lo. A partir do ato do consumo, a marca transfere seus valores conceituais e simbólicos a quem a utiliza, influenciando diretamente o posicionamento social e a identidade do público. Uma vez que o sujeito forma a sociedade, na medida em que sofre modificações, consequentemente, a identidade cultural também se modifica. É claro o fato de a cultura ter a sua essência e seus conceitos inerentes, porém é possível observar mutações sociais influenciadas por diferentes fatores que agregam características e estimulam reações no sujeito para que convivam em sociedade.

\section{Referências}

AAKER, D. A. Construindo marcas fortes. Porto Alegre: Bookman, 2007.

BAUMAN, Z. Vida líquida. Rio de Janeiro: Jorge Zahar, 2007.

CIAMPA, A. C. A estória do Severino e a história da Severina: um ensaio de psicologia social. 2. ed. São Paulo: Brasiliense, 1990.

LIPOVETSKY, G. A felicidade paradoxal: ensaio sobre a sociedade de hiperconsumo. São Paulo: Companhia das Letras, 2007.

STRATTON, P.; HAYES, N. Dicionário de Psicologia. São Paulo: Pioneira, 1994.

TAVARES, M. C. Gestão de marcas: construindo marcas de valor. São Paulo: Harbra, 2008.

Recebido: 15/03/2010

Received: 03/15/2010

Aprovado: 29/03/2010

Approved: 03/29/2010 